\title{
A u-shaped backward masking function in vision'
}

\author{
Naomi Weisstein, UNIVERSITY OF CHICAGO \\ Ralph Norman Haber, UNIVERSITY OF ROCHESTER
}

\begin{abstract}
Abstraet
Errors in discriminating the letters $\mathrm{O}$ and $\mathrm{D}$ in a forced-choice design were measured with 4 Ss when the exposure of either letter was accompanied or followed by a ring encircling it. The delay between offset of the letter and onset of the ring varied from concurrent presentation of both, through $0 \mathrm{msec}$. delay to $120 \mathrm{msec}$. delay, in steps of $10 \mathrm{msec}$. The letter and ring were presented randomly in one of four positions in a centrally located row, with the other three positions always empty. Accuracy was a u-shaped function of the delay between letter and ring for all 4 Ss. An explanation of the discrepancy between these findings and those of Eriksen \& Collins (1964) is offered.

\section{Problem}

Recent studies in this Journal have indicated that visual masking follows either a decreasing monotonic function with respect to delay in either direction between a target and mask (Eriksen \& Collins, 1964; Eriksen \& Lappin, 1964), or a function with zero slope (Mayzner et al., 1964). The shapes of these functions have been the basis for the rejection of the "erasure" concept (Averbach \& Coriell, 1961) since there should be no erasure with concurrent presentation nor with forward masking. ${ }^{2}$ Rather, masking is explained as a reduction in discriminability of the target due either to the complexity of the initial array, or to its reduction in contrast by luminance summation.

Eriksen and his associates have argued on the basis of theses studies that the $\mathrm{u}$-shaped functions of backward masking previously reported (e. g., Kolers, 1962; Werner, 1935; Alpern, 1953; Toch, 1956) are artifactual. Specifically, they criticize the lack of concurrentpresentation of target and mask, and the indicator methodology employed. They suggest that since neither payoff matrices nor a forced-choice design was used, it was possible that Ss were changing their detection criteria with different delays. The purpose of the present study is to show that these u-shaped functions for backward masking are obtainable even after Eriksen's criticisms are met.

\section{Methoo:}

The stimali, letters $O$ and $D$, were presented in a three-channel niirror tachistoscope (Scientific Prototype Mfg. Corp, Model D). Each of four Ss was tested individually. In each session, $\mathrm{S}$ first dark-adapted for 1 min. and then light-adapted to a blank visual field illuminated at $9.4 \mathrm{ft}-\mathrm{L}$. A black fixation point of less than 2 ' was present in the center of the field. The luminance was constant for all three fields, and all fields were viewed binocularly. The letter was exposed for $20 \mathrm{msec}$. in one field, and then the ring for $50 \mathrm{msec}$. in another

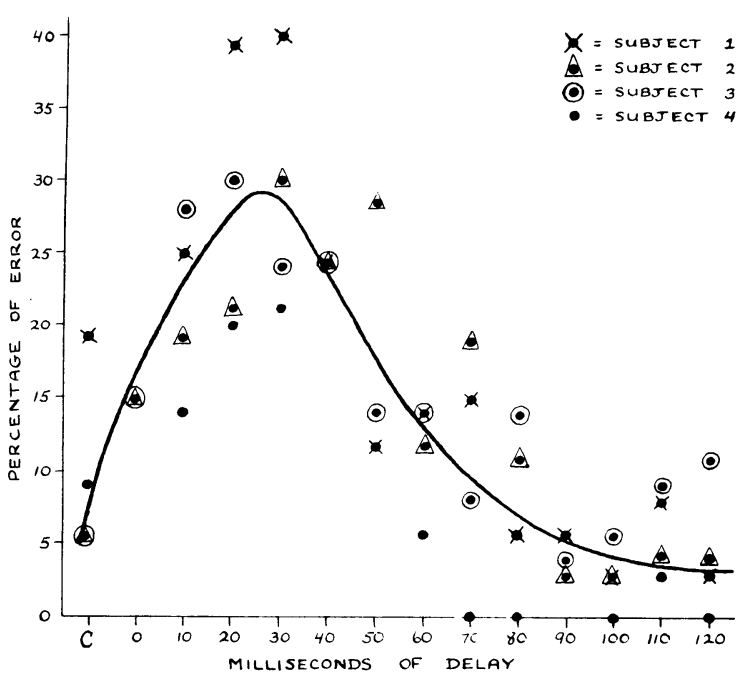

Fig. 1. Errors out of 64 trials for each of four subjects at each of 14 delay intervals.

field. Delay between offset of letter and onset of ring was automatically programmed and controlled by a card punch (Haber et al., 1962) so that the delay intervals were presented in random order in very session for every S. Only two Ss were tested at 0 delay, though all Ss were tested at all of the other delay intervals. There were 64 trials for each $S$ at each delay interval. $S$ was required to respond either "O" or "D"'; a "no" response was not permitted.

Each letter subtended $0.30^{\circ}$ horizontally by $0.62^{\circ}$ vertically, with a thickness of $0.08^{\circ}$. The angular distances between the fixation point and the center of a letter was $0.61^{\circ}$ for the letter appearing in the two middle positions, and $1.73^{\circ}$ for those in the two outside positions. The masking ring had an inner diameter of $0.61^{\circ}$ and a thickness of $0.05^{\circ}$. The angular separation between the outer edge of the letter and the inner edge of the ring was $0.083^{\circ}$. The two letters and the ring had a contrast of 0.95 .

\section{Results}

The measure of masking was the percentage of errors at each delay interval. Inspection of Fig. 1 shows clear $\mathrm{u}$-shaped functions for each $\mathrm{S}$, with no reversals up to the first maximum. An analysis of variance indicated that delay interval was significant at beyond the $1 \%$ level, and for each S separately, the difference between concurrent and the maximum was significant beyond at least the $3 \%$ level. Thus, for all Ss, stimuli presented concurrently with a mask were reported more accurately 
(a mean error of $12 \%$ ) than when the mask was delayed from 20 to $40 \mathrm{msec}$. (a mean error of approximately $30 \%)$. Further, this masking function returns to the same or lower levels as concurrent presentation after a delay of 70 to $90 \mathrm{msec}$. (approximately 6\% error). That there was some masking even at concurrent presentation is shown by comparison with data from another condition with the same Ss, where no ring was presented in the second field. Here, the error was $3 \%$, significantly less than the $12 \%$ at beyond the $1 \%$ level.

\section{Diseussion}

Masking of one letter by a ring is a u-shaped function of the delay between offset of the letter and onset of the ring for the letters $\mathrm{O}$ and $\mathrm{D}$ when ring and letters are of identical and high contrast, and the letters and ring vary randomly in one of four horizontal positions. This is consistent with earlier findings on the conditions under which u-shapes will obtain (Kolers, 1962). Further, it is consistent with earlier findings on the requirements for angular separation needed in order to get $\mathrm{u}$-shaped masking effects (Alpern, 1953). The only exception to the angular distance rule is the work of Averbach \& Coriell, where a u-shape was obtained for any letter in the alphabet when there was more than one letter in the stimulus field. Weisstein (1964) showed that masking increased as the number of items in the array increased. Thus it is possible that the contour requirements of the masking stimulus are not as strict as the array increases, and target patterns may vary with respect to angular separation and still be masked. It is entirely plausible, then, that Eriksen should find no u-shaped masking for the letters $A, T$, and $M$ which he used when they were presented singly. Rather, the masking obtained would be monotonically related to delay, as Kolers (1962) found for stimuli of low contrast. Thus the discrepancy between these data and the recent masking studies of Eriksen reflect the established differences in the literature on visual backward masking. (See Raab, 1963, for a general summary of backward masking.)

It is important to establish, however, that u-shaped functions are in fact obtainable, since they are of great theoretical interest; they indicate at least a two-phase process in perceptual recognition in which a later phase is particularly sensitive to disruption by additional visual stimulation. This, in turn, suggests a minimum estimate of perceptual processing time which is not as clearly implied by the monotones; and it suggests that any theory which implicitly views perceptual processing itself as immediate or undifferentiated temporally will be insufficient to explain visual backward masking in general, since, according to such a view, any masking effect must decay monotonically with time.

\section{Referenees}

ALPERN, M. Metacontrast. J. Opt. Soc. Amer., 1953, 43, 648-657. AVERBACH, E., \& CORIELL, A. S. Short-term memory in vision. Bell Sys. tech. J., 1961, 40, 309-328.

ERIKSEN, C. W., \& COLLINS, J. F. Backward masking in vision. Psychon. Sci., 1964, 1, 101-102.

ERIKSEN, C. W., \& LAPPIN, J. S. Luminance summation-contrast reduction as a basis for certain forward and backward masking effects. Psychon. Sci., 1964, 1, 313-314.

HABER, R. N., HERSHENSON, M., \& SCHROEDER, D. Apparatus note: The use of an IBM 024 or 026 card punch for simultaneous stimulus programing and response recording. Percept. mot. Skills, $1962,15,627-630$.

KOLERS, P. A. Intensity and contour effects in visual masking. Vis. Res., 1962, 2, 277-294.

MAYZNER, M. S., ABREVAYA, E. L., FREY, R. E., KAUFMAN, H. G., \& SHOENBERG, K. M. Short-term memory in vision: a partial replication of the Averbach and Coriell study. Psychon. Sci., 1964, 1, 225-226.

RAAB, D. H. Backward masking. Psychol. Bull., 1963, 60, 118-129. TOCH, H. H. The perceptual elaboration of stroboscopic presentation. Amer. J. Psychol., 1956, 69, 345-358.

WEISSTEIN, NAOMI. Temporal aspects of perceptual systems. Unpublished doctoral dissertation, Harvard University, 1964. WERNER, H. Studies in contour: I. qualitative analyses. Amer. J. Psychol., 1935, 47, 40-64.

Notes

1. This research was completed at Yale University and supported in part by a United States Public Health Service Grant MH-03244 to the second author.

2. It should be noted that the rejection of "erasure" as the mechanism in masking does not necessarily reject the short-term visual information storage model of Averbach \& Coriell (1961) or Sperling (1963). It merely rejects the notion that this short-term visual image is sensitive to erasure from incoming stimuli. 